\title{
Synergism of Pratylenchus penetrans and Verticillium dahliae Manifested by Reduced Gas Exchange in Potato
}

\author{
Ibrahim A. M. Saeed, Ann E. MacGuidwin, and Douglas I. Rouse
}

Department of Plant Pathology, University of Wisconsin, 1630 Linden Drive, Madison 53706.

Accepted for publication 14 January 1997.

\section{ABSTRACT}

Saeed, I. A. M., MacGuidwin, A. E., and Rouse, D. I. 1987. Synergism of Pratylenchus penetrans and Verticillium dahliae manifested by reduced gas exchange in potato. Phytopathology 87:435-439.

The effects of solitary and concurrent infection by Pratylenchus penetrans and Verticillium dahliae on gas exchange of Russet Burbank potato (Solanum tuberosum) were studied in growth chamber experiments. Treatments were $P$. penetrans at low, medium, and high density; $V$. dahliae alone at one initial density; the combination of the nematode at these three densities and $V$. dahliae; and a noninfested control. Gas exchange parameters of leaf cohorts of different ages in the different treatments were repeatedly measured with a Li-Cor LI-6200 portable photosynthesis system. At 45 days after planting, joint infection significantly reduced net photosynthesis, stomatal conductance, and transpiration of 1- to 25-day- old leaf cohorts. Intercellular $\mathrm{CO}_{2}$ levels were significantly increased by co-infection, especially in older leaves. The synergistic effect of co-infection on gas exchange parameters was greater in the oldest cohort than in the youngest cohort. No consistent effects on leaf gas exchange parameters were observed in plants infected by the nematode or the fungus alone. The relationship between the assimilation rate and stomatal conductance remained linear regardless of solitary or concomitant infection, indicating that stomatal factors are primarily responsible for regulating photosynthesis. The significant reduction of gas exchange in leaves of co-infected plants without reduction in intercellular $\mathrm{CO}_{2}$ concentrations suggests that nonstomatal factors also play a role when both organisms are present.

Additional keywords: light use efficiency, potato early dying, root-lesion nematode, water use efficiency.
Potato early dying disease is manifested by wilted foliage, premature senescence, and decreased tuber yield. The disease is caused by Verticillium dahliae Kleb. alone or in conjunction with other organisms, including the root-lesion nematode Pratylenchus penetrans (Cobb) Filipjev \& Schuurmanns Stekhoven $(17,18,26$, 31 ). A synergistic interaction between $V$. dahliae and $P$. penetrans at low population densities affecting symptom expression and yield reduction of potato cultivars Russet Burbank (17), Superior $(18,24,25)$, Reddale (31), and Kennebec (31) has been demonstrated. The disease caused by joint infection of nematodes and $V$. dahliae appears similar to that caused by the fungus alone, which has led researchers to attribute the interaction to enhanced pathogenesis of $V$. dahliae when the nematode is present $(10,23)$. Although several theories have been offered to explain the mechanism of the interaction $(8,10,11,23,31)$, none has addressed the effects of the interacting pathogens on the basic crop physiological functions of gas exchange and water relations.

The impact of $V$. dahliae on gas exchange in potato has been described $(2-4,9)$. Bowden and Rouse (2) found that solitary infection by $V$. dahliae reduced transpiration, stomatal conductance, and photosynthesis of Russet Burbank potato leaves. Haverkort et al. (9), studying the interaction between $V$. dahliae and potato in the field, found significant changes in stomatal conductance and gas exchange characteristics of Saturna potato 1 month after emergence.

The yield loss demonstrated for joint infection by $V$. dahliae and $P$. penetrans could be due to reduced photosynthetic capacity of potato leaves, decreased leaf area resulting from compromised plant growth, or dysfunctional partitioning of assimilates to tuber production. We repeated the experiments of Bowden and Rouse

Corresponding author: A. E. MacGuidwin

E-mail address: macguid@ macc.wisc.edu

Publication no. P-1997-0228-01R

(C) 1997 The American Phytopathological Society
(2) using low inoculum levels of the fungus and the nematode $P$. penetrans. The objective of this study was to determine whether there was a synergistic interaction of these two organisms affecting potato gas exchange. Preliminary reports of portions of this study were previously published (28). The time course of the individual and joint effects of the nematode and the fungus and the relationship of the initial nematode inoculum dose to disease expression are reported elsewhere (27).

\section{MATERIALS AND METHODS}

Experiments were conducted in a growth chamber at the University of Wisconsin Biotron, a controlled plant growth facility. The same treatment structure and experimental design (randomized complete block with four replications) were used in all experiments, but the nematode inoculum dose varied between experiments. Treatments were $P$. penetrans at low density $(0.8$ and 1.3 nematodes per $\mathrm{cm}^{3}$ of soil in experiments 1 and 2 , respectively), medium density (1.8 and 2.7 nematodes per $\mathrm{cm}^{3}$ of soil), and high density ( 2.5 and 4.1 nematodes per $\mathrm{cm}^{3}$ of soil); Verticillium alone; Verticillium combined with the nematode at the three different densities; and a noninfested control.

Plantlets of Russet Burbank potato (Solanum tuberosum L.) were propagated from tissue culture. The cuttings were grown in test tubes for about 20 days and then were transferred to $10-\mathrm{cm}$ clay pots packed with Jiffy mix. The plantlets were kept in a growth chamber at $24^{\circ} \mathrm{C}$ for hardening for about 15 days and were then transplanted into 20-liter plastic pots containing a 1:1 mixture of Plainfield loamy sand (92\% sand, 5\% silt, 3\% clay, and $<1 \%$ organic matter) and vermiculite pasteurized at $75^{\circ} \mathrm{C}$ for 30 min. Each plant produced a single main stem, which was staked upright to facilitate gas exchange measurements. Axillary branches were pruned to three basal branches per main stem. When a stem terminated in an inflorescence, the first subapical branch was considered the new main stem. 
Light was supplied by cool white fluorescent lamps $\left(1,270 \mathrm{~W} \mathrm{~m}^{-2}\right.$ at the top of the chamber) and incandescent lamps $\left(474 \mathrm{~W} \mathrm{~m}^{-2}\right)$. The lights were turned on at $0600 \mathrm{~h}$, and the photoperiod was $14 \mathrm{~h}$. Relative humidity was maintained at $50 \% \pm 5 \%$. The temperature was $25^{\circ} \mathrm{C} \pm 0.5^{\circ} \mathrm{C}$ during the day and $15^{\circ} \mathrm{C} \pm 0.5^{\circ} \mathrm{C}$ at night. The plants were automatically watered to excess with $1 / 4$ Hoagland's solution twice daily for the first 2 weeks and then four times daily thereafter until the end of the experiment. Carbon dioxide levels were maintained by continuously supplying fresh air to the room. Investigators wore gas masks connected to a vacuum pump vented outside the chamber to prevent breathing on the plants during measurements and to maintain a constant $\mathrm{CO}_{2}$ level in the chamber.

Inoculum production and soil infestation. A Wisconsin isolate of $V$. dahliae (WI V-18), in vegetative compatibility group 4A (12), was grown on sterile rye seed at $20^{\circ} \mathrm{C}$ for 5 weeks. The rye
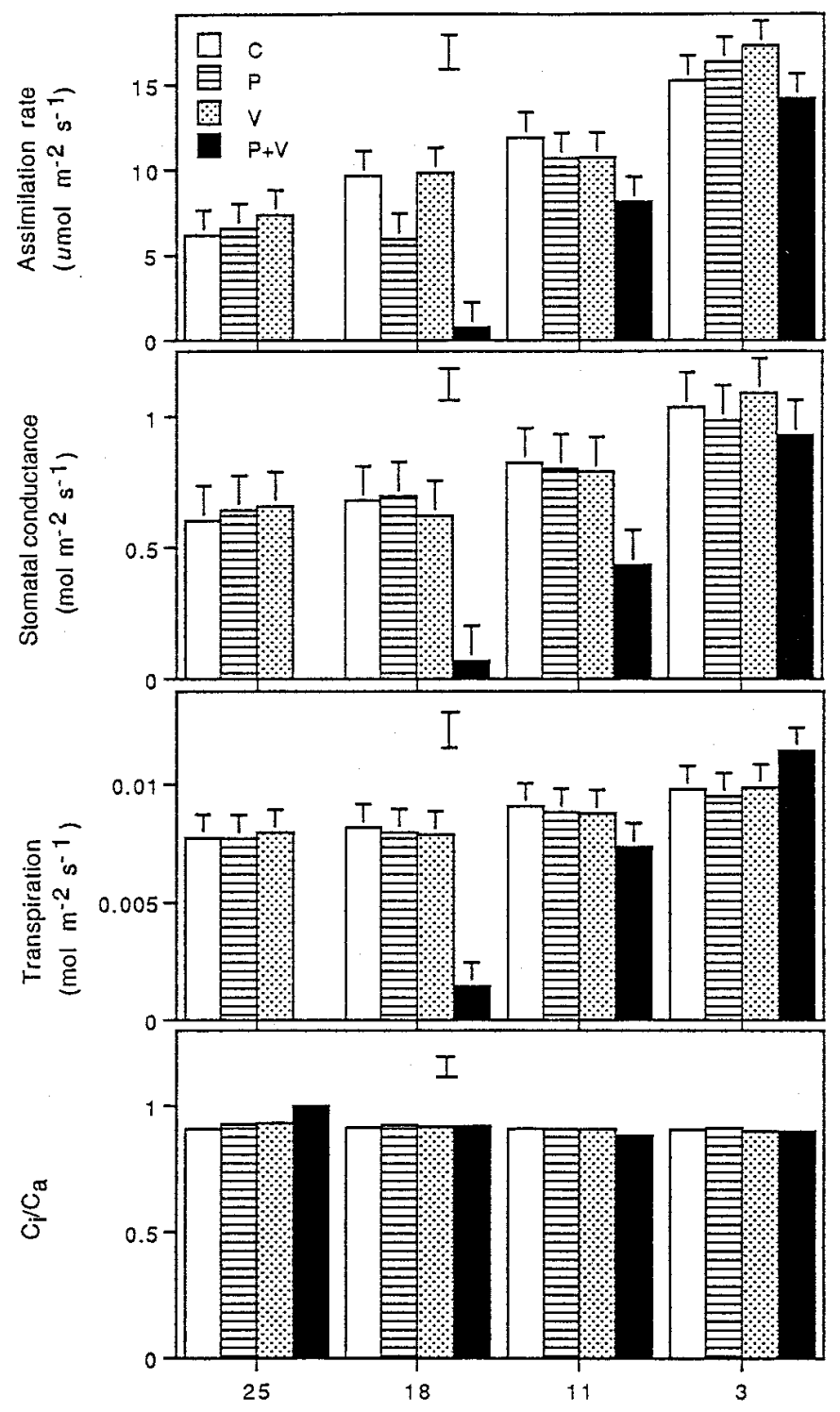

Leaf cohort age (Days)

Fig. 1. Effects of potato early dying on gas exchange in cohorts of leaves of different ages on Russet Burbank potato plants in experiment 1 at 45 days after planting: uninoculated control plants (C, open columns), plants inoculated with Pratylenchus penetrans (P, columns with horizontal lines), plants inoculated with Verticillium dahliae (V, dotted columns), and plants jointly inoculated with both pathogens ( $\mathrm{P}+\mathrm{V}$, solid columns). $\mathrm{C}_{\mathrm{i}} / \mathrm{C}_{\mathrm{a}}$ is the ratio of intercellular $\mathrm{CO}_{2}$ concentration to ambient $\mathrm{CO}_{2}$ concentration. Each value is a mean of four replications. The error bars above the columns and those in the upper parts of the graphs are least square differences for comparing treatments at the same cohort age and at different cohort ages, respectively. seed culture was air-dried for 2 weeks at room temperature and then ground in a Wiley mill. Inoculum was applied at the rate of $0.5 \mathrm{~g} /$ liter of soil mix and was thoroughly incorporated by hand before soil was added to the pots. The density of the added inoculum was 40 propagules per $\mathrm{g}$ of soil, as determined by dilution plating. Inoculum of $V$. dahliae recovered from infested soil at the end of the experiments averaged 5.4 propagules per $g$ of soil.

$P$. penetrans isolated from potato in Wisconsin was reared on sweet corn explants (cultivar I. O. Chief) grown on Gamborg's B-5 medium without auxins or cytokinins. Nematodes were collected by rinsing and incubation methods (16). Nematode inoculum was added to the pots by means of a $20-\mathrm{ml}$ syringe at the time of transplanting. A depression approximately $20 \mathrm{~cm}$ deep and 10 $\mathrm{cm}$ wide was made with a trowel in the middle of the packed pot, and the nematode inoculum was spread directly on the soil in the
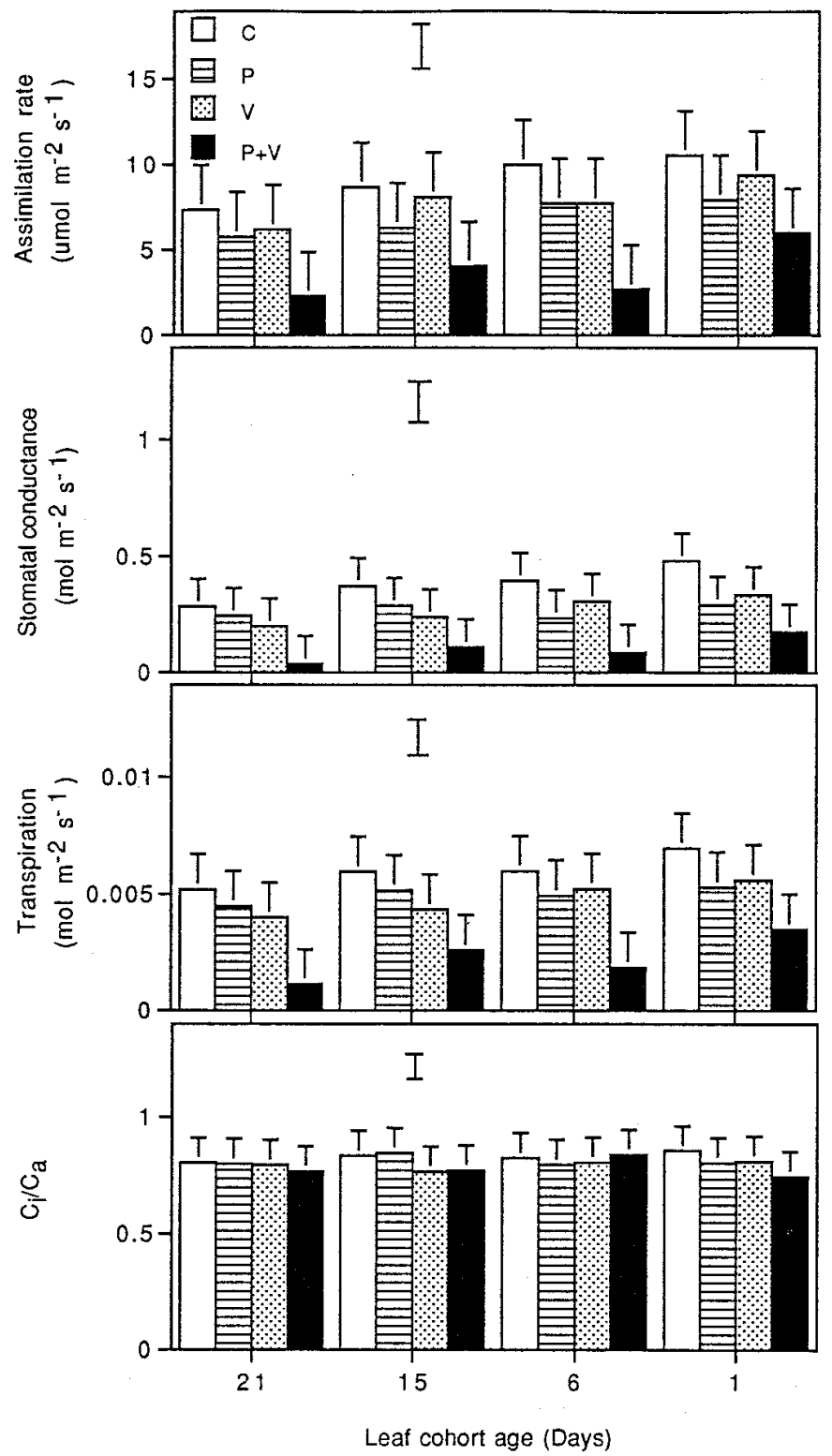

Fig. 2. Effects of potato early dying on gas exchange in cohorts of leaves of different ages on Russet Burbank potato plants in experiment 2 at 42 days after planting: uninoculated control plants (C, open columns), plants inoculated with Pratylenchus penetrans (P, columns with horizontal lines), plants inoculated with Verticillium dahliae (V, dotted columns), and plants jointly inoculated with both pathogens $\left(\mathrm{P}+\mathrm{V}\right.$, solid columns). $\mathrm{C}_{\mathrm{i}} / \mathrm{C}_{\mathrm{a}}$ is the ratio of intercellular $\mathrm{CO}_{2}$ concentration to ambient $\mathrm{CO}_{2}$ concentration. Each value is a mean of four replications. The error bars above the columns and those in the upper parts of the graphs are least square differences for comparing treatments at the same cohort age and at different cohort ages, respectively. 
hole. The number of nematodes added ranged from 0.8 to 4.1 per $\mathrm{cm}^{3}$ of soil, depending on the experiment. A seedling was then placed in the hole. The hole was filled with soil, and the soil was packed around the seedling.

Gas exchange measurements. The terminal leaflets of the youngest fully expanded, fully lit leaves were selected and tagged for gas exchange measurements. Leaf tagging started about 20 days after transplanting (DAP). Leaves tagged on a particular day are referred to as a cohort. Cohorts were labeled 1, 2, 3, etc., from oldest to youngest, respectively. Seven leaf cohorts per plant were tagged in experiment 1 , and nine in experiment 2 . The difference in the total number of leaf cohorts tagged was due to differences in plant growth rates and the length of the experiments. Gas exchange measurements were taken on all tagged leaves one to three times per week. An LI-6200 portable photosynthesis system (LiCor, Lincoln, NE) with a 0.25 -liter chamber was used for the gas exchange measurements. Carbon assimilation rates, stomatal conductance, transpiration, and other related parameters were measured or calculated.

Statistical analysis. Gas exchange of all cohorts was analyzed as a split-plot design with plants as the main experimental unit and leaf cohorts as the subplot within plants. Because of the senescence of the oldest leaf cohorts, the data sets were unbalanced. A value of zero was assigned to abscised leaves for photosynthesis, stomatal conductance, and transpiration. Intercellular $\mathrm{CO}_{2}$ concentrations $\left(\mathrm{C}_{\mathrm{i}}\right)$ in these leaves were assumed to be equal to ambient $\mathrm{CO}_{2}$ concentrations $\left(\mathrm{C}_{\mathrm{a}}\right)$. To minimize the impact of leaf senescence on data interpretation, only data collected for leaf cohorts 1 to 4 at 45 DAP (experiment 1) or 42 DAP (experiment 2) are presented here. On these dates most plants were flowering, and leaves from only one cohort and treatment in one experiment were senesced. Analysis of variance was performed on this bal-

TABLE 1. Summary of repeated measure analysis of the gas exchange variables in Russet Burbank potato inoculated with Verticillium dahliae (Vert), Pratylenchus penetrans (Nema), or both pathogens ${ }^{\mathrm{a}}$

\begin{tabular}{|c|c|c|c|c|c|}
\hline \multirow[b]{2}{*}{ Source of variation } & \multirow[b]{2}{*}{$\mathrm{df}^{\mathrm{b}}$} & \multicolumn{2}{|c|}{ Experiment 1} & \multicolumn{2}{|c|}{ Experiment 2} \\
\hline & & $\mathrm{MS}^{\mathrm{c}}$ & $P$ value ${ }^{\mathrm{d}}$ & $\mathrm{MS}^{\mathrm{c}}$ & $P$ value $^{\mathrm{d}}$ \\
\hline \multicolumn{6}{|l|}{ Assimilation rate } \\
\hline Cohort & 3 & 824.9 & 0.00 & 33.4 & 0.00 \\
\hline Cohort* Block & 9 & 5.8 & 0.32 & 2.7 & 0.65 \\
\hline Cohort * Vert & 3 & 50.6 & 0.00 & 7.1 & 0.12 \\
\hline Cohort $*$ Nema & 9 & 11.1 & 0.03 & 4.0 & 0.36 \\
\hline Cohort $*$ Vert $*$ Nema & 9 & 8.5 & 0.09 & 5.5 & 0.15 \\
\hline Error & 63 & 4.9 & & 3.0 & \\
\hline \multicolumn{6}{|l|}{ Stomatal conductance } \\
\hline Cohort & 3 & 2.12 & 0.00 & 0.13 & 0.00 \\
\hline Cohort* Block & 9 & 0.04 & 0.11 & 0.02 & 0.03 \\
\hline Cohort* Vert & 3 & 0.26 & 0.00 & 0.02 & 0.11 \\
\hline Cohort $*$ Nema & 9 & 0.02 & 0.66 & 0.01 & 0.44 \\
\hline Cohort $*$ Vert $*$ Nema & 9 & 0.03 & 0.22 & 0.02 & 0.72 \\
\hline Error & 63 & 0.02 & & 0.01 & \\
\hline \multicolumn{6}{|l|}{ Transpiration } \\
\hline Cohort & 3 & 0.00 & 0.00 & 0.00 & 0.00 \\
\hline Cohort* Block & 9 & 0.00 & 0.73 & 0.00 & 0.31 \\
\hline Cohort $*$ Vert & 3 & 0.00 & 0.00 & 0.00 & 0.52 \\
\hline Cohort $*$ Nema & 9 & 0.00 & 0.00 & 0.00 & 0.28 \\
\hline Cohort $*$ Vert $*$ Nema & 9 & 0.00 & 0.00 & 0.00 & 0.69 \\
\hline Error & 63 & 0.00 & & 0.00 & \\
\hline \multicolumn{6}{|l|}{ Intercellular $\mathrm{CO}_{2}$} \\
\hline Cohort & 3 & 0.01 & 0.00 & 0.00 & 0.00 \\
\hline Cohort* Block & 9 & 0.00 & 0.25 & 0.00 & 0.56 \\
\hline Cohort $*$ Vert & 3 & 0.01 & 0.00 & 0.00 & 0.12 \\
\hline Cohort $*$ Nema & 9 & 0.00 & 0.00 & 0.01 & 0.36 \\
\hline Cohort $*$ Vert $*$ Nema & 9 & 0.00 & 0.03 & 0.01 & 0.15 \\
\hline Error & 63 & 0.00 & & 0.01 & \\
\hline
\end{tabular}

${ }^{a}$ Data collected 45 days after planting in experiment 1 and 42 days after planting in experiment 2.

b Degrees of freedom based on split-plot analysis of variance.

c Type III mean square.

${ }^{\mathrm{d}} P$ value from $F$ test based on degrees of freedom. anced data with SAS procedure GLM using the REPEATED statement (SAS Institute, Cary, NC). Least significant differences for comparing subplot treatments within the same whole plot or in different whole plots were calculated according to Milleken and Johnson (21).

\section{RESULTS}

There was a highly significant reduction of leaf gas exchange in plants inoculated with both $P$. penetrans and $V$. dahliae, compared to the control (Figs. 1 and 2). Gas exchange differed significantly between leaf cohorts (Table 1 and Figs. 1 and 2). Not all of the difference was due to leaf age. There were no significant differences between treatments with different levels of initial $P$. penetrans inoculum (28). Therefore, data from treatments with the high level of nematode inoculum in each experiment were chosen for presentation in Figures 1 and 2.

The carbon assimilation rate of leaf cohorts ranging from 1 to 25 days old was reduced in jointly infected plants, compared to

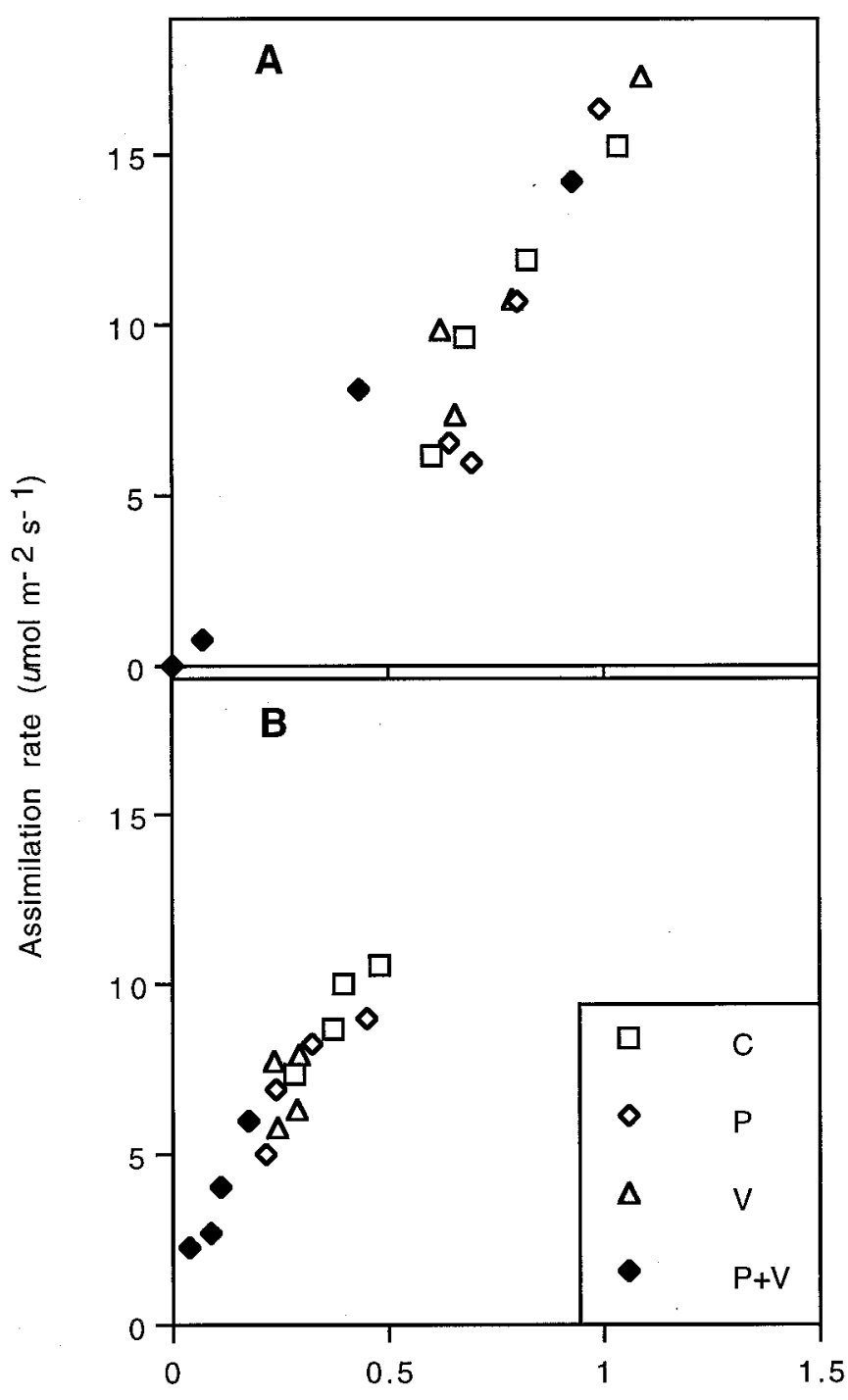

\section{Stomatal conductance $\left(\mathrm{mol} \mathrm{m} \mathrm{m}^{-2} \mathrm{~s}^{-1}\right)$}

Fig. 3. Effects of potato early dying on the relationship between carbon assimilation rate and stomatal conductance in cohorts of leaves of different ages on Russet Burbank potato plants A, in experiment 1 at 45 days after planting and $\mathbf{B}$, in experiment 2 at 42 days after transplanting: uninoculated control plants (C, squares), plants inoculated with Verticillium dahliae (V, triangles), plants inoculated with Pratylenchus penetrans ( $\mathrm{P}$, open diamonds), and plants jointly inoculated with both pathogens $(\mathrm{P}+\mathrm{V}$, solid diamonds). Each value is from an individual leaf. 
the control (Figs. 1 and 2). In general, this difference in assimilation rates increased as the leaves aged, but the magnitude of the effect varied between experiments. Infection by $V$. dahliae alone had no effect on the assimilation rate, and only one leaf cohort in one experiment showed reduced carbon assimilation after inoculation with the nematode only.

Reduced $\mathrm{CO}_{2}$ assimilation in plants inoculated with $V$. dahliae and $P$. penetrans at a level of approximately 2 or 4 nematodes per $\mathrm{cm}^{3}$ of soil was accompanied by reductions in stomatal conductance and transpiration (Figs. 1 and 2). The differences in stomatal conductance were more pronounced in experiment 1. In 18-day-old leaves, values for stomatal conductance in jointly infected plants were $89 \%$ lower than those of control plants, and even in the youngest leaves (3 days old) values were $10 \%$ lower than those of the controls. Reduced transpiration was evident in all leaves except the youngest leaves in experiment 1 . Stomatal conductance and transpiration were always lower in jointly infected plants than in plants infected with nematodes only, and they were lower in jointly infected plants than in plants infected with $V$. dahliae only, except in one leaf cohort in experiment 1 . Infection by nematodes

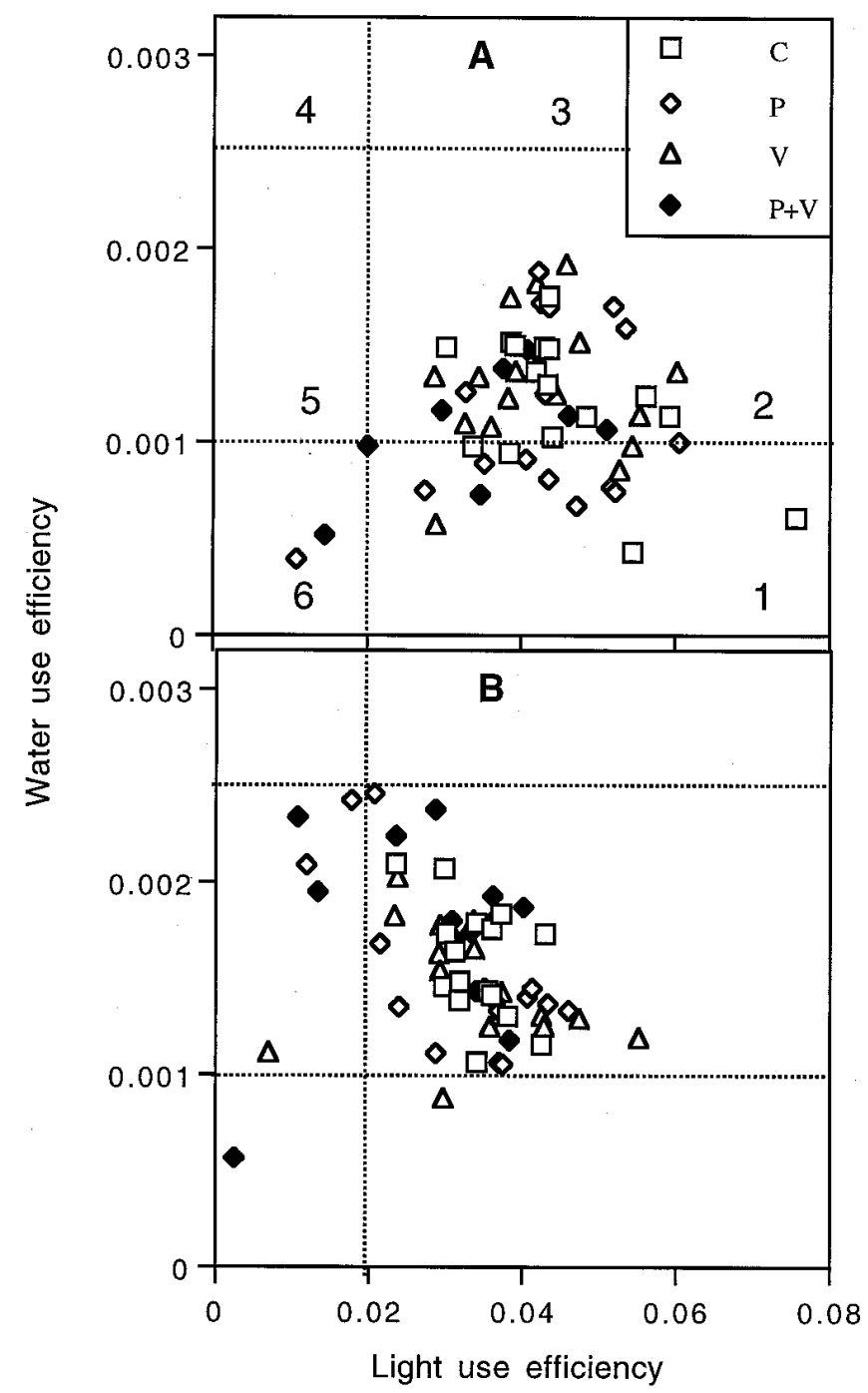

Fig. 4. Effects of potato early dying on the relationship between light use efficiency (mol of $\mathrm{CO}_{2}$ fixed per mol photon) and water use efficiency (mol of $\mathrm{CO}_{2}$ fixed per mol of water transpired) in cohorts of leaves of different ages on potato plants $\mathbf{A}$, in experiment 1 at 45 days after planting and $\mathbf{B}$, in experiment 2 at 42 days after planting: uninoculated control plants (C, squares), plants inoculated with Verticillium dahliae (V, triangles), plants inoculated with Pratylenchus penetrans ( $\mathrm{P}$, open diamonds), and plants jointly inoculated with both pathogens $(\mathrm{P}+\mathrm{V}$, solid diamonds). Each value is from an individual leaf. or Verticillium alone had no effect on transpiration and affected stomatal conductance only in experiment 2.

The ratio of intercellular $\mathrm{CO}_{2}$ to ambient $\mathrm{CO}_{2}$ was significantly elevated in older leaves of jointly infected plants, compared to the controls, in experiment 1 (Fig. 1); the ratio was not significantly changed in experiment 2 (Fig. 2). Leaves in the oldest cohort were already dead at 45 days after planting in experiment 1 , so the high values assigned to them convey little information, but the older leaves in experiment 2 were functional. In no case was the $\mathrm{CO}_{2}$ ratio reduced in co-infected plants. Concentrations of $\mathrm{CO}_{2}$ in plants infected with only one pathogen were not different from those of the control plants.

Decreased leaf net photosynthesis was correlated with reduced stomatal conductance in plants in the combination treatments (Fig. 3 ). The leaf assimilation rate and stomatal conductance of the control, nematode-infected, and Verticillium-infected plants were high, compared to the concomitantly infected plants. However, in plants with solitary or concomitant infections, the same linear relationship between the assimilation rate and stomatal conductance was observed.

The relationship between water use efficiency (WUE, in mol of $\mathrm{CO}_{2}$ fixed per mol of water transpired) and light use efficiency (LUE, in mol of $\mathrm{CO}_{2}$ fixed per mol of photosynthetically active radiation used) of infected and uninfected individual leaves of different ages is depicted in Figure 4. Each graph is divided into six sections, after Bowden and Rouse (2), to classify leaves according to their health status. The healthy leaves of the control plants fell in sections 1 and 2 and exhibited relatively constant LUE in experiments 1 and 2. Leaves from plants infected with either pathogen alone or with both pathogens fell in sections 1,2 , 5 , and 6. Leaves on concomitantly infected plants first exhibited decreased LUE and increased WUE (n. 4B) and then exhibited a decrease in both efficiency values. Leaves on Verticillium-infected or nematode-infected plants showed a similar trend but with more variability among the different cohorts, compared to the concomitantly infected plants. No leaves from the jointly infected plants fell in sections 3 or 4 .

\section{DISCUSSION}

The gas exchange of plants infected with both $V$. dahliae and $P$. penetrans was compromised when the plants were inoculated with the fungus and the nematode at levels that had no effect when either was used alone. Since the sum of the effects of each pathogen alone was small compared to the combined effects, a highly significant synergistic interaction affecting gas exchange was demonstrated. Reductions in carbon assimilation rate, transpiration, and stomatal conductance in leaves ranging from 1 to 25 days old were not accompanied by a reduction in intercellular $\mathrm{CO}_{2}$. This indicates that the malfunction was due not simply to local plugging of the xylem vessels but rather to a combination of stomatal and nonstomatal factors. The difference between gas exchange in leaves of uninoculated controls and that in leaves of concomitantly infected plants increased as the leaves aged, which corresponds to the most pronounced symptom associated with this nematode-fungus interaction, accelerated senescence.

Reduced $\mathrm{CO}_{2}$ assimilation rate, transpiration rate, and stomatal conductance of concomitantly infected plants are consistent with a deleterious effect of $V$. dahliae on the hydraulic conductance of the xylem. Stomatal closure caused by impaired water flow would be expected to decrease photosynthesis. Data of Bowden and Rouse (2) for potato infected with high levels of $V$. dahliae are consistent with a mechanism of stomatal closure to explain reductions in photosynthesis and were corroborated by a field study by Haverkort et al. (9). The latter researchers demonstrated that following infection with $V$. dahliae photosynthesis of potato was reduced early in growth as a result of drought stress in the leaves. The reduction was more pronounced in older leaves and older plants. 
Interaction of drought and $V$. dahliae was partly explained by the reduction of transpiration due to $V$. dahliae which reduced drought.

Neither $V$. dahliae nor $P$. penetrans alone, at the low levels used in this study, had a consistent effect on gas exchange parameters, but joint infection by these pathogens reduced gas exchange without reducing intercellular $\mathrm{CO}_{2}$. This finding suggests that the physiological response of Russet Burbank potato to concomitant infection is different from the response to infection by the fungus alone (2). Other nonstomatal factors may be involved in reducing photosynthesis in jointly infected plants. An alternative explanation for this is that since the inhibition of the assimilation rate and the decrease in stomatal conductance of co-infected plants were of similar magnitude, only stomatal closure is responsible for the decrease in photosynthesis, and that there was bias and overestimation of $\mathrm{C}_{\mathrm{i}}(5,30)$ due to patchiness in the distribution of photosynthesis across individual leaves.

The increase in leaf WUE of plants infected by $V$. dahliae alone at high levels could be accounted for by a decrease in $C_{i}$ brought about by stomatal closure (2). In our study, however, leaves on concomitantly infected plants exhibited lower WUE, since coinfection caused a more drastic reduction in photosynthesis than in transpiration. Reduction in stomatal conductance alone cannot explain all of the reduction in $\mathrm{CO}_{2}$ assimilation in joint infection. This provides additional evidence that nonstomatal factors were involved in the reduction of leaf gas exchange due to the presence of the nematode in the system.

Earlier investigations have shown reduced gas exchange parameters due to infection of potato and other crops by root-knot and cyst nematodes $(1,6,7,15,19,20,22,29)$. It was concluded that reduced photosynthesis could be due to either stomatal closure or inhibition of the production of cytokinins, gibberellins, and auxins in the host plant. In the present study, the reduced gas exchange due to infection by $P$. penetrans in the presence of the fungus could also be attributed to both stomatal and nonstomatal factors. Neither our experiments nor previous studies $(13,14)$ demonstrated a significant impact of $P$. penetrans infection on gas exchange.

This study is the first report on effects of infection by $P$. penetrans alone or in combination with $V$. dahliae on carbon assimilation rates of potato in situ. It is also the first report of synergistic effects of the two pathogens on potato gas exchange. This paper is followed by another report that describes the temporal effects of solitary and joint infection on symptom development and gas exchange in Russet Burbank potato (27).

\section{ACKNOWLEDGMENTS}

This research was supported by USDA-ARS competitive grant \#581275-1-136 and USDA-NRI competitive grant \#92-3702-7609. We thank T. D. Sharkey for his cooperation and M. Clayton for statistical assistance.

\section{LITERATURE CITED}

1. Bird, A. F. 1959. The attractiveness of roots to the plant parasitic nematodes, Meloidogyne javanica and M. hapla. Nematologica 1:322-335.

2. Bowden, R. L., and Rouse, D. I. 1991. Effects of Verticillium dahliae on gas exchange of potato. Phytopathology 81:293-301.

3. Bowden, R. L., and Rouse, D. I. 1991. Chronology of gas exchange effects and growth effects of infection by Verticillium dahliae in potato. Phytopathology 81:301-310.

4. Bowden, R. L., Rouse, D. I., and Sharkey, T. D. 1990. Mechanism of photosynthesis decrease by Verticillium dahliae in potato. Plant Physiol. 94:1048-1055.

5. Downton, W. J. S., Loveys, B. R., and Grant, W. J. R. 1988. Stomatal closure fully accounts for inhibition of photosynthesis by abscisic acid. New Phytol. 108:263-266.

6. Duniway, J. M., and Slatyer, R. O. 1971. Gas exchange studies on the transpiration and photosynthesis of tomato leaves affected by Fusarium oxysporum f. sp. lycopersici. Phytopathology 61:1377-1381.

7. Fatemy, F., Trinder, P. K. E., Wingfield, J. N., and Evans, K. 1985. Effect of Globodera rostochiensis water stress and oxogeneris abscisic acid on stomatal function and water use of Cara and Pentland Dell potato plant. Rev. Nematol. 8:249-255.

8. Garber, R. H. 1973. Fungus penetration and development. Pages 69-77 in: Verticillium Wilt of Cotton. USDA-ARS-519. C. D. Ranney, ed. National Cotton Pathology Research Lab, College Station, TX.

9. Haverkort, A. J., Rouse, D. I., and Turkensteen, L. J. 1990. The influence of Verticillium dahliae and drought on potato crop growth. 1. Effects on gas exchange and stomatal behavior of individual leaves and crop canopies. Neth. J. Plant Pathol. 96:273-289.

10. Huisman, O. C. 1982. Interrelations of root growth dynamics to epidemiology of root-invading fungi. Annu. Rev. Phytopathol. 20:303-327.

11. Isaac, I., and Harrison, J. A. C. 1968. The symptoms and causal agents of early-dying disease (Verticillium wilt) of potatoes. Ann. Appl. Biol. 61:231-244.

12. Joaquim, T. R., and Rowe, R. C. 1991. Vegetative compatibility and virulence of strains of Verticillium dahliae from soil and potato plants. Phytopathology 81:552-558.

13. Kaplan, D. T., Tattar, T. A., and Rohde, R. A. 1976. Reduction of electrical resistance in sunflower roots infected with lesion nematodes. Phytopathology 66:1262-1264.

14. Kotcon, J. B., and Loria, R. 1986. Influence of Pratylenchus penetrans on plant growth and water relations in potato. J. Nematol. 18:385-392.

15. Koenning, S. R., and Barker, K. R. 1995. Soybean photosynthesis and yield as influenced by Heterodera glycines, soil type and irrigation. J. Nematol. 27:51-62.

16. Layne, T. L., and MacGuidwin, A. E. 1994. Recovery of Pratylenchus penetrans from plant tissue cultures. (Abstr.) J. Nematol. 26:557.

17. MacGuidwin, A. E., and Rouse, D. I. 1990. Role of Pratylenchus penetrans in the potato early dying disease of Russet Burbank potato. Phytopathology 80:1077-1082.

18. Martin, M. J., Riedel, R. M., and Rowe, R. C. 1982. Verticillium dahliae and Pratylenchus penetrans: Interactions in early dying complex of potato in Ohio. Phytopathology 72:640-644.

19. Melakeberhan, H., Brooke, R. C., Webester, J. M., and D' Auria, J. M. 1985. The influence of Meloidogyne incognita on growth, physiology and nutrient content of Phaseolus vulgaris. Physiol. Plant Pathol. 26:259-268.

20. Meon, S., and Fisher, J. M. 1978. Water relations of tomato infected with Meloidogyne javanica Treub. Chitwood. Physiol. Plant Pathol. 13:275-281.

21. Milleken, G. A., and Johnson, D. E. 1984. Analysis of Messy Data. Vol. 1, Designed Experiments. Van Nostrand Reinhold, New York.

22. Poskuta, J. W., Dropkin, V. H., and Nelson, C. J. 1986. Photosynthesis, photorespiration and respiration of soybean after injection with root nematodes. Photosynthetica 20:405-410.

23. Riedel, R. M., and Rowe, R. C. 1985. Lesion nematode involvement in potato early dying disease. Am. Potato J. 62:163-171.

24. Riedel, R. M., Rowe, R. C., and Martin, M. J. 1985. Differential interactions of Pratylenchus crenatus, $P$. penetrans, and P. scribneri with Verticillium dahliae in potato early dying disease. Phytopathology 75:419-422.

25. Rowe, R. C., Davis, J. R., Powelson, M. L., and Rouse, D. I. 1987. Potato early dying: Causal agents and management strategies. Plant Dis. 71:482-489.

26. Rowe, R. C., Riedel, R. M., and Martin, M. J. 1985. Synergistic interactions between Verticillium dahliae and Pratylenchus penetrans in potato early dying disease. Phytopathology 75:412-418.

27. Saeed, I. A. M., MacGuidwin, A. E., and Rouse, D. I. 1994. Interactive effects of Pratylenchus penetrans and Verticillium dahliae on potato gas exchange. (Abstr.) Phytopathology 84:1090.

28. Saeed, I. A. M., MacGuidwin, A. E., and Rouse, D. I. 1997. Disease progress based on effects of Verticillium dahliae and Pratylenchus penetrans on gas exchange in Russet Burbank potato. Phytopathology 87:440-445.

29. Schans, J., and Anitzen, F. K. 1991. Photosynthesis, transpiration and plant growth characters of different potato cultivars at various densities of Globodera pallida. Neth. J. Plant Pathol. 97: 297-310.

30. Terashima, I., Wong, S.-C., Osmond, C. B., and Farquhar, G. D. 1988. Characterization non-uniform photosynthesis induced by abscisic acid in leaves having different mesophyll anatomies. Plant Cell Physiol. 29:385394.

31. Wheeler, T. A., Rowe, R. M., Riedel, R. M., and Madden, L. V. 1994. Influence of cultivar resistance to Verticillium spp. on potato early dying. Am. Potato J. 71:39-57. 